\title{
Els valors cooperatius de la responsabilitat en la participació i l'equitat. Una proposta didàctica a l'educació primària
}

\author{
Víctor Grau, Marcel•lí Piñana \\ Universitat Rovira i Virgili \\ vgraufe@gmail.com; mpinana@xtec.cat
}

Resum: L'educació en valors cooperatius contribueix a la formació de la ciutadania des de paràmetres cívics i democràtics. La participació responsable persegueix que les actuacions individuals permetin la intervenció positiva en el conjunt de la societat. L'equitat facilita l'assoliment de la igualtat entre els individus des d'un repartiment just dels recursos.

Partint de lanàlisi de resultats d'una primera pràctica aplicada a dos centres d’educació primària, s'aposta per la continuïtat en la prospecció didàctica amb la incorporació de nous eixos de treball $i$ altres escoles.

Paraules clau: diàleg, igualtat, compromis, justícia, cooperació.

Abstract: When cooperative parameters are studied, we discover a lot of civic and democratic values. Individual actions can produce big changes in society, and a fair sharing out of resources and money makes equal citizens in the world.

After a practice approximation in two schools, this model will be applied in other primary schools, including new working axis.

Keywords: dialogue, equality, commitment, justice, cooperation.

\section{Del moviment cooperatiu a l'educació en valors}

El modest moviment cooperatiu nascut a Rochadle l'any 1844 va anar consolidant-se progressivament en el temps $i$ en l'espai fins al punt que actualment més de mil milions de persones estan adherides a alguna entitat cooperativa. El cooperativisme modern, social i econòmic, deu lèxit a la fidelitat als seus principis, els quals, fixats per l'Aliança Cooperativa Internacional (ACI), són els següents: adhesió voluntària i oberta sense discriminació de gènere, raça, classe social, posició política o religiosa; control democràtic per part dels seus membres; participació econòmica dels socis; autonomia i independència; educació, formació i informació; cooperació entre cooperatives, i compromís amb la comunitat.

D’aquests principis se'n desprenen valors formatius que investigadors reconeguts del cooperativisme han definit amb la finalitat de millorar l'acció educativa a partir del desenvolupament dels punts següents: necessitat de diàleg i consens; valoració d'idees divergents; llibertat quant a tenir idees pròpies; igualtat en la presa de decisions; responsabilitat en la tolerància, la comunicació, les opinions, els desitjos, l'acord, la negociació, la participació; la democràcia com a norma de respecte; el fet d'aprendre a saber i valorar 
opinions; l'economia en regulació, i la constància i la persistència en la implicació (Gavaldà, 2000).

Al capdavall, des de la perspectiva docent es tracta d'aprofitar les possibilitats didàctiques que pugui aportar la cooperació a la millora educativa concretat en un tema pedagògic de vigent actualitat com és el de l'educació en valors. Va ser precisament en el marc de la didàctica de les ciències socials de la Facultat de Ciències de l'Educació i Psicologia de la URV que es va constituir un grup de treball de vuit professors amb l'objectiu primordial d'investigar i reflexionar sobre els valors cooperatius i la seva aproximació pràctica a l'educació primària. Fruit de la recerca en vam seleccionar dos de força útils per la projecció vital en la formació de l'alumnat i en la integració en la societat: la responsabilitat en la participació i l'equitat.

\section{La responsabilitat en la participació}

Abans d'abordar aquest primer valor, vam sospesar la possibilitat de desplegar-lo com si es tractés de dos termes independents: responsabilitat, d'una banda, i participació, de l'altra. Després de reflexionar conjuntament sobre el tema, vam concloure de manera unànime que es tracta de dos conceptes que necessàriament havien d'anar units i entrelligats per escometre l'acció educativa: la participació reclama responsabilitat i la responsabilitat, participació.

La responsabilitat ha de ser un acte fonamentalment individual encara que s'ha de donar en comunitat. La responsabilitat és un dels valors més preuats i necessaris per assolir-ne altres amb els quals manté interacció com són la justícia, la llibertat, l'equitat, l'honradesa, la igualtat, la solidaritat o la transparència. I la millor forma d'assolir els drets individuals és participar activament en la comunitat, però entesa des de la responsabilitat individual a la col-lectiva, és a dir, vers la millora i el bé comú de la societat.

Un dels treballs més destacats sobre participació social de l'alumnat és el que formulà Hart (1993), que van concretar posteriorment Trilla i Novella (2001), els quals van establir nivells diferenciats de participació. L'últim nivell classificat exigeix la necessitat de fomentar instruments bàsics per promoure-la. Considerem que cal fo- mentar l'afecte als altres, la tolerància, la comunicació, les opinions, els desitjos, l'acord, la negociació, els consensos.

\section{Lescola com a espai de participació respon- sable}

La responsabilitat en la participació s'ha de promoure des d'edats ben primerenques $i$ en tots els àmbits possibles de participació, el primer dels quals és el familiar. Però l'espai necessari de participació ha de ser l'escola i en aquest recinte cal destacar l'acció educativa a l'aula, encara que també existeixen altres espais de participació com són el pati, el menjador o la biblioteca.

De fet, és a l'aula on s'assignen els càrrecs unipersonals que contribueixen al bon funcionament de la classe i a la millora del clima de relació entre tots els membres.

Freire (1970) indicava que el diàleg és una exigència existencial i no sés persona si no es fa mitjançant el diàleg. Precisament per això la responsabilitat en la participació pot abordar-se des de l'àrea de ciències socials, des de la quotidianitat apostant per activitats en grup de temàtica actual com la pau, l'ecologia, la distribució de recursos, els drets humans, la violència de gènere, l'explotació infantil, les guerres i els conflictes armats, la discriminació social, les migracions actuals. I des de la dinàmica cooperativa, en què la màxima que ha d'imperar en el grup - entre d'altres- és la coneguda doble responsabilitat: tot membre d'un grup ha d'aprendre els continguts $i$, ensems, s'ha de preocupar que els seus companys també ho aprenguin (Pujolàs, 2003).

\section{Laplicació a l'escola: exercicis i resultats}

Amb l'objectiu d'identificar el grau d'assumpció del valor de la responsabilitat en la participació en l'àmbit de l'educació primària, vam confeccionar uns exercicis d'exploració adequats a l'alumnat de cada cicle sense indicacions prèvies o amb poques. La mostra corresponent es va aplicar a un centre públic de Tarragona de nivell socioeconòmic mitjà estructurada a través de vuit ítems de treball. Una vegada efectuada i examinada la prova, vam destacar els resultats següents: 
a) Conèixer les eines de participació

Els nens van entendre que un debat no era una competició on s'imposaven els arguments d'uns sobre els altres i l'exercici de la votació en determinats casos resultava útil però s'havia d'emprar únicament en darrer terme, quan calia escollir una opció entre altres i no existia cap altra possibilitat de consens.

b) Elegir els càrrecs

Lalumnat de cicle inicial propugnava la necessitat d'una gestió compartida i responsable per assegurar l'ordre a l'aula. Els alumnes van admetre que un treball acurat havia de disposar de la recerca de mesures per corregir conflictes que poguessin sorgir.

\section{c) Prendre decisions col-lectivament}

Lexercici vinculat a aquest eix proposava als alumnes de cicle mitjà realitzar una activitat de camp a una explotació agrícola amb el dilema que s'havia de decidir si s'havia de dur a terme al mateix municipi o a una altra població. Es va posar de manifest que els costava prendre un decisió definitiva. I a la fi, esgotades les propostes i els arguments, a manca d'acord els va quedar patent que en aquests casos l'única via de resolució era la votació.

\section{d) El diàleg, una pràctica democràtica}

Lexercici dirigit als nens de cicle inicial exigia trobar una solució a un conflicte d'ambient lúdic. Davant de la situació real de no disposar de prou joguines per a tots els xiquets, van reflexionar sobre el fet que tots, sense excepció, havien de tenir loportunitat de jugar. Tanmateix, la concepció cooperativista no es va apreciar suficientment, ja que gran part de l'alumnat es va inclinar pel sistema de torns.

A l'activitat dissenyada per a cicle mitjà, buscar característiques pròpies de la democràcia i la dictadura, no van acabar d'aclarir suficientment els conceptes.

e) Ser capaç de modificar l'opinió

A partir d'un debat es plantejava als nens de cicle mitjà realitzar unes colònies escolars a la platja o a la muntanya. En el desenvolupament del corresponent debat un de cada quatre alumnes de la classe va acabar modificant l'opinió a partir d'arguments concrets ben expressats i de manera coherent per altres companys.

\section{f) Establir compromisos}

Lexercici dirigit a cicle superior descobria l'actuació d'un alumne que no desenvolupava responsablement la seva funció de delegat de classe. Per la gran part de l'alumnat el cas reclamava la intervenció directa del mestre en la resolució del conflicte. Altres aportacions discents apuntaven vers reaccions típicament sancionadores com substituir el delegat. En alguns casos eren més subjectives, per exemple les relacions d'amistat amb el company encausat.

\section{g) Buscar solucions}

Lactivitat adreçada a cicle superior requeria resoldre una situació problemàtica entre dos alumnes. Amb relació a la resolució, es va produir una pluralitat de reaccions, encara que els xiquets coincidien a fer-ho saber al mestre. Tanmateix, només en alguns casos van entendre que la resta d'alumnes també eren elements protagonistes i que tenien la seva part de responsabilitat davant d'una situació que afectava o podia afectar tot el grup.

h) Actuar amb responsabilitat, justícia i solidaritat

Des de la geografia dels conflictes a partir d'un mapa actual del continent africà, es tractava de fer reflexionar l'alumnat de cicle superior sobre les causes directes i indirectes de les guerres, les seves conseqüències i possibles actuacions. Per sobre de tot, la gran majoria dels alumnes va destacar la poca eficàcia dels agents de pau en la resolució dels conflictes i va apostar decididament per promoure valors pacifistes.

\section{L'equitat: la concreció del terme}

Evidentment, l'elecció d'aquest segon valor per desplegar a l'escola no es va produir de manera aleatòria. Preteníem resoldre, en primer lloc, la confusió habitual existent entre dos conceptes que contenen aspectes comuns: equitat $i$ igualtat. Aquest darrer es pot considerar l'objectiu teleològic del primer. Enteníem que la millor forma per determinar l'equitat era fer-ho des d'una reflexió teoricopràctica concretada en una proposta d'activitats.

Definir equitat i establir les característiques essencials del terme era també un dels objectius que preteníem assolir. Entenem que l'equitat vol acon- 
seguir la igualtat d'oportunitats dels individus a partir del repartiment proporcional i just dels recursos. No implica oferir la mateixa quantitat a totes les persones, sigui quina sigui la seva condició, sinó que es tracta d’aportar la quantitat necessària requerida en cada situació. L'equitat, per tant, es relaciona directament amb el reconeixement soci$\mathrm{al}$, atès que persegueix resultats beneficiosos per al conjunt de la societat (Cannon, 1982).

Equitat i justícia. Quan parlem de justícia no l'entenem com l'aplicació estricta de la llei, sinó com una eina correctora de la norma que permet adaptar-se en cada cas. "Lequitat simbolitza la diferència, la particularitat, l'especialitat, enfront de la llei, que expressa la idea d'igualtat" (Falcón, 2005).

Equitat $i$ individualitat. Lequitat cerca que tothom tingui els recursos necessaris (Moreno, 2007) amb la intenció de garantir les mateixes condicions i la igualtat d'oportunitats sense distincions tot respectant la individualitat. Reconèixer les diferències individuals permet descobrir millores futures per tal d'aconseguir ser autènticament equitatius, així com acceptar la diversitat i la unicitat de cada individu (Kagan, 1995).

\section{La necessitat d'impulsar el valor de l'equitat a l'escola}

Considerem necessari vehicular l'equitat a l'escola, ja que pot contribuir a la vertebració d'una societat molt més democràtica i igualitària des de la formació de nous ciutadans. Lescola i les ciències socials esdevenen un àmbit privilegiat de participació que permet afavorir formes de pensar i actuar en un sentit equitatiu més enllà del context educatiu. És l'hora de fer front a contravalors que en l'actualitat tenen un fort impacte en la societat: l'egoisme, la competitivitat, la corrupció.

Desenvolupar l'equitat a l'aula implica que l'alumne aprengui ja, des de l'etapa d'educació infantil, a reconèixer situacions injustes, a cedir, a compartir, a cooperar, a cercar el benefici col-lectiu i a mostrar empatia. Implica, doncs, entendre que amb aquestes actituds tothom hi surt guanyant. Per fer-ho possible cal crear els denominats "espais de nens" (García-Peinado et alii, 2011) on es puguin plantejar diverses pers- pectives, formes d'expressió, diàleg, confrontació i pensament crític.

Però res d'això no té sentit si no trobem eines funcionals que fomentin la participació de l'alumnat i el tractament de conceptes associats a l'equitat (justícia, democràcia, cooperació i igualtat).

\section{De la teoria a l'aula: anàlisi de resultats}

De la reflexió teòrica bastida en els darrers apartats vam presentar un conjunt d'activitats vinculades a l'equitat amb la intenció d'aplicar-les a alumnes dels tres cicles d'educació primària. Lamplitud semàntica del concepte ens obligà a formular una sèrie d'eixos sobre els quals estructurar les activitats: justícia amb adaptació a les circumstàncies individuals, justícia amb empatia, igualtat d'oportunitats, valoració de la individualitat, solidaritat intrageneracional i intergeneracional, equitat ambiental, resposta a les necessitats escolars individuals amb reducció de les discriminacions, igualtat de gènere i compliment de drets i deures.

Per tal de dur a terme les corresponents comprovacions de l'estat de la qüestió de l'alumnat en matèria dequitat, vam decidir intervenir només en dos punts concrets: justícia amb empatia i resposta a les necessitats escolars individuals amb reducció de les discriminacions. Es concretaren sis blocs d'activitats pautades amb la intenció de mesurar la comprensió del concepte, el cicle on s'observava més conflictivitat a l'hora d'entendre'l i determinar en quin cicle seria necessari incidir-hi amb més intensitat.

L'escola que seleccionàrem per analitzar l'estat de la qüestió és diferenciada, de sexe femení; aquest fet ens suscità en quina mesura aquesta homogeneïtat podria afectar els resultats obtinguts.

A cicle inicial es va dissenyar un bloc de nou activitats introduïdes per un breu text que presentava una situació simulada. El tema de la pràctica descobria la necessitat d'ajudar i ser ajudat a partir d'una situació conflictiva protagonitzada per un alumne que era al pati en horari d'esbarjo. El conjunt de les activitats girava entorn d'un posicionament personal, així com formes d'ajudar l'alumna implicada per tal d'evitar situ- 
acions conflictives posteriors, iguals o similars. Del total de vint-i-dues alumnes implicades en la prova, tres manifestaren no haver assumit el concepte d'ajuda; d'aquestes alumnes, en l'activitat de reflexió en grup que es va realitzar posteriorment, només una mantingué el mateix posicionament inicial.

A cicle mitjà confeccionàrem un bloc de vuit activitats que treballaven la capacitat empàtica des d'una simulació en què un alumne, bon futbolista, no podia jugar a un altre esport - també preferit per ell-per manca de demanda del grup classe. El total de les nenes entengueren que existeixen gustos diferents dels propis i que han de ser necessàriament respectats i valorats.

Pel que fa al cicle superior, es formulà un bloc de sis activitats que pretenien desenvolupar la capacitat de respectar les diferències entre elles mateixes i també comprendre la capacitat d'adaptació. El tema presentava la relació existent entre dues germanes bessones narrada gràficament en quatre imatges. Les alumnes, en la seva totalitat, van posar l'èmfasi en la necessitat de marcar singularitats individuals, respecte per l'espai propi i les relacions socials individuals.

\section{Conclusions}

En aquesta primera aproximació als valors cooperatius que vehicula el present article, hem pogut constatar que, en general, les activitats practicades han estat motivadores per a l'alumnat dels tres cicles d'educació primària i han despertat el seu interès; al nostre parer, perquè es tractava de circumstàncies i casos reals, propers i quotidians a ells i a l'aula. Tots els alumnes han manifestat lliurement el seu punt de vista i han exposat les seves propostes personals davant de les diferents situacions proposades. És obvi que unes activitats han estat més motivadores que unes altres. En el cas concret de la responsabilitat en la participació, tractant-se d'una escola amb força famílies immigrants, el resultat de la mostra ha estat considerada satisfactòria en els tres cicles d'educació primària.

En el cas del segon valor de la intervenció, el de l'equitat, les respostes han estat força positives; l'alumnat ha mostrat un domini apreciable del valor conscients, tanmateix, de tractar-se d'una escola diferenciada. Especialment destaquem que la noció d'equitat i, en particular, el component de justícia amb empatia es pot començar a fomentar des de ben petits. Al cicle mitjà i superior poden construir-se argumentacions més complexes per trobar solucions als problemes o a les situacions proposades. Al cicle superior tenen més desenvolupada la noció d'individualitat i de personalitat pròpia sense que això representi un obstacle per a una comprensió més precisa de la noció de justícia i dels problemes que pateixen altres persones.

Per tant, amb relació a l'educació en aquests valors cooperatius, apostem per la continuitat en la recerca aplicada, i fer-la extensible a altres centres d'educació primària des d'un plantejament obert intentant millorar i completar aquesta línia de treball amb la incorporació de nous eixos de treball i d'aprofundiment dels que han estat objecte d'aquesta primera aproximació pràctica a l'escola.

\section{Referències bibliogràfiques}

CAnnon, J. (1982). "La integración de valores cooperativos y personales en ayuda al aprendizaje". $R C I, 4,29-35$.

Falcón y Tella, M. J. (2005). Equidad, derecho y justicia. Madrid: Centro de Estudios Ramón Areces.

Freire, P. (1970). Pedagogía del oprimido. México: Siglo XXI.

García-Peinado, R., et alii (2011). "Enseñar la justicia social en educación infantil". Revista Iberoamericana sobre Calidad, Eficacia $y$ Cambio en Educación, vol. 9, 4, 94-113.

GavaldÀ, A. (2000). "Com abordar valors cooperatius a l'ensenyament?". Cooperació Catalana, 226, 14-17.

HART, R. (1993). La participación de los niños: de la participación simbólica a la participación auténtica. Bogotà: Nueva Gente.

Moreno Herrera, L. (2007). "Equity, equality and equivalence. A contribution in search for conceptual definitions and a comparative methodology". Revista Española de Educación Comparada, 13, 319-340.

Pujolàs, P. (2003). Aprendre junts alumnes diferents. Vic: Eumo Editorial. 